Claves. Revista de Historia, Vol. $4, \mathrm{~N}^{\circ} \cdot 7$

Montevideo, julio - diciembre 2018

(pp. 165-169) ISSN 2393-6584

\title{
Esto ha sido. Encuentro de Investigación sobre fotografía e historia en Uruguay
}

Clara von Sanden

Universidad de la República, Uruguay

Citando a Roland Barthes en una de las frases que explican su interpretación sobre la naturaleza de la fotografía, el Centro de Fotografía de Montevideo -con el apoyo del Centro Cultural de España- dió comienzo en el mes de julio de este año a un ciclo -que se espera que continúe en adelante- de encuentros de reflexión académica desde diversas disciplinas acerca de la fotografía.

Esto ha sido congregó a investigadores de diversas áreas, profesionales, docentes y estudiantes para reflexionar en torno a herramientas, experiencias y modos de conocer a través de la fotografía. Con una justificación basada en el crecimiento y expansión del uso y circulación de imágenes en los últimos años, y la consiguiente proliferación de estudios diversos sobre el fenómeno, el evento se planteó como objetivo extender el interés y la discusión académica más allá de la era digital. Quiénes producen las imágenes, con qué fines, cómo se construyen, qué efectos producen en quienes las consumen y qué estrategias deben seguirse para interpretarlas, son sólo algunas de las preguntas que se presentan como necesarias para comprender imágenes de todas las épocas.

Desde el Centro de Fotografía se ha constatado que en Uruguay las reflexiones académicas y las experiencias didácticas que parten del uso de imágenes para conocer y problematizar la historia están todavía poco desarrolladas. Existen experiencias desde campos como la historiografía, la antropología, la sociología, las ciencias de la comunicación, la didáctica, entre otras, pero aún faltaban instancias de intercambio y sistematización de experiencias y conocimientos locales, algo con lo que esta actividad pretende colaborar.

El evento comenzó con la presentación de la investigadora argentina invitada Andrea Cuarterolo, quien expuso a través de diversos ejemplos el uso de la escenificación en la fotografía de la prensa ilustrada a inicios del siglo XX y su 
vínculo con los primeros noticieros de cine en distintos lugares de Latinoamérica. En consonancia con sus últimos trabajos, en los que aborda la relación entre fotografía y cine en este período, Cuarterolo mostró a través de varios ejemplos las prácticas de la prensa ilustrada y del noticiero de actualidades para la construcción de la noticia, colaborando a comprender en su contexto, a partir de un análisis minucioso de algunos ejemplos, cómo los reporteros gráficos de la época creaban ambientes e incluso lograban sortear limitaciones técnicas para brindar las mejores y más verosímiles imágenes de los hechos sociales relevantes, o de aquellos cuyo registro jerarquizaría como tales.

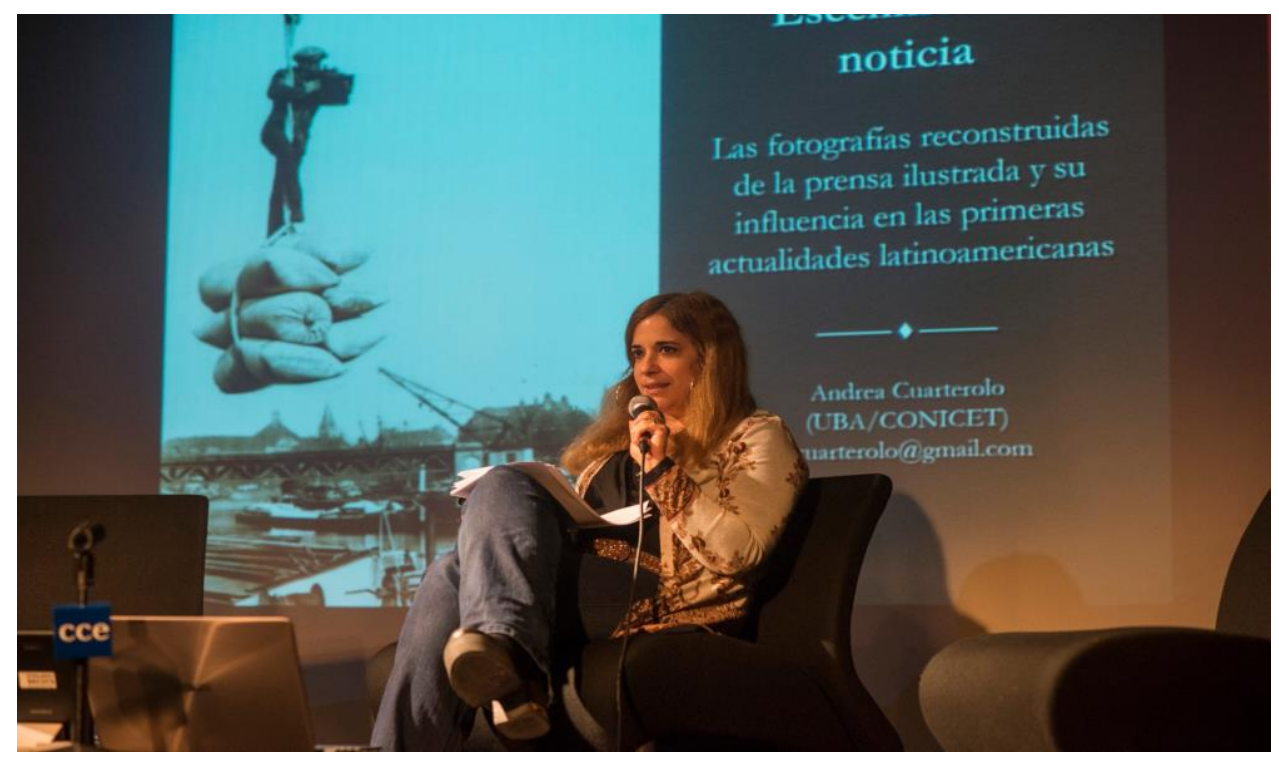

Andrea Cuarterolo

Foto: Centro de Fotografía de Montevideo.

Las docentes Ana Buela y Magdalena de Torres expusieron varias experiencias específicas de uso de fotografías en la enseñanza de la Historia en el nivel secundario, a través de ejercicios pensados para el trabajo en el aula en los cursos de tercero y cuarto año. En la presentación pudo observarse un método de trabajo de didáctica de la historia a través de series de fotografías, con diversos niveles de análisis y ciertas tareas mediante las cuales se propone a los estudiantes una mirada crítica sobre ellas y su contexto de creación y circulación, así como sus distintas funciones. Su propuesta tiene como desafío, por una parte, proponer un acercamiento distinto a la comprensión de los procesos históricos, y por otra, colaborar a una mirada crítica de la fotografía, "desmitificar la verdad de la foto" en pro de una observación informada y detenida por parte de los estudiantes. 
La presentación del Gonzalo Vicci expuso el aporte de las artes plásticas y los estudios culturales en un análisis interdisciplinario del consumo de vino a comienzos del siglo XX. En su presentación mostró al público algunas de las bases teóricas en que su trabajo se apoya y algunos ejemplos de estrategias publicitarias e imágenes de prensa contrarias al consumo de vino, que disputaban la opinión pública con piezas que promocionaban este producto.

Desde el Museo Histórico Nacional, Andrés Azpiroz y Jorge Sierra realizaron una concisa presentación de la colección de fotografías que el Museo alberga, que constituye una de las más extensas, variadas y valiosas colecciones de esta clase en el país. Su ponencia se centró en las medidas adoptadas por el museo en los últimos años en pro de conservar y conocer mejor la colección en sus diversas partes.

La investigadora Ana María Rodríguez Ayçaguer expuso una ponencia titulada Fotografía, Estado y sentimiento patriótico en el Uruguay de Terra. El registro fotográfico de la "Cruzada Cultural” de 1934. En ella mostró al público varios de sus avances en la búsqueda y análisis de un conjunto documental numeroso que permite apreciar en detalle un evento hasta el momento casi no advertido por los trabajos historiográficos sobre el período: la apuesta del gobierno de Terra de acercar, mediante el uso de varios vagones de ferrocarril preparados especialmente para la ocasión, objetos de museo, obras pictóricas, libros de autores nacionales, entre otros, a una muy extensa lista de localidades del interior del país.

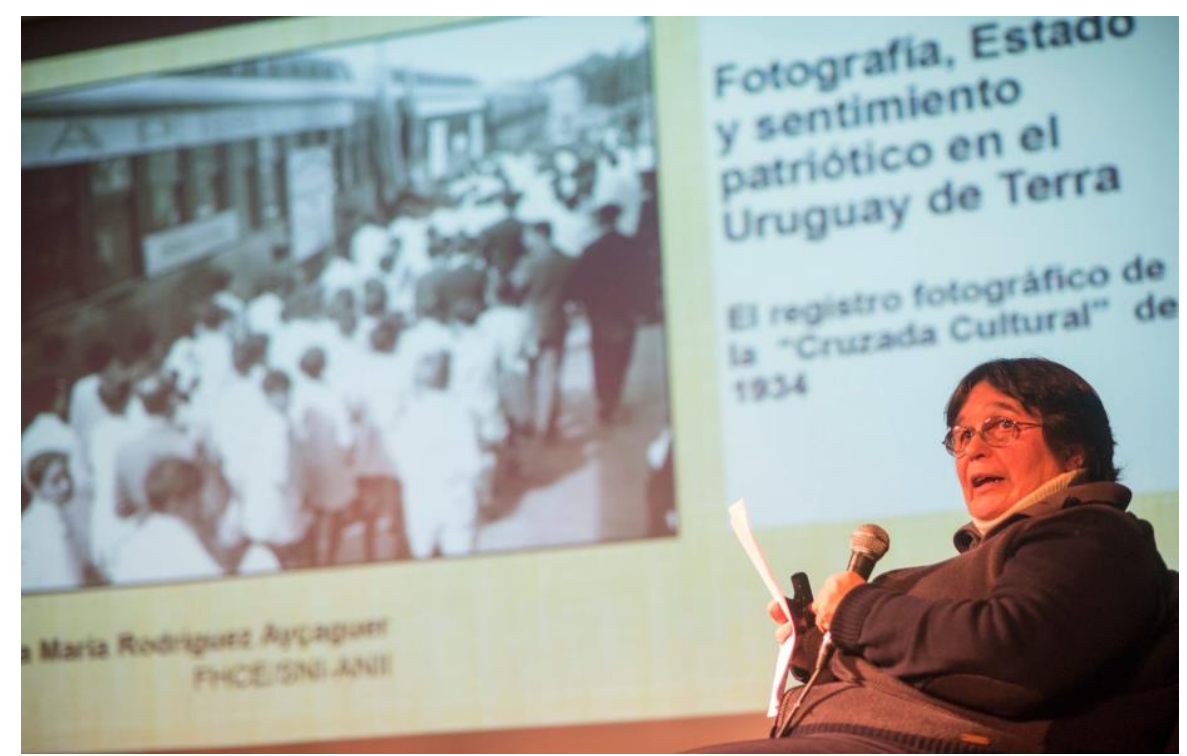

Ana María Rodríguez Ayçaguer durante su presentación.

Foto: Centro de Fotografía de Montevideo. 
Desde la arqueología, Elena Saccone y Nicol De León expusieron un panorama del uso actual de la fotografía en su disciplina, mostrando algunas de las potencialidades que ofrece como fuente de información y de intercambio acerca de un sitio o material arqueológico. Tanto para analizar la historia de un terreno o edificio y sus cambios, como la composición y asociación de materiales unos con otros, el estudio del deterioro y sus causas, la realización de entrevistas y actividades de sensibilización acerca del patrimonio arqueológico, así como el estudio volumétrico en su tridimensionalidad a través de la fotogrametría, la fotografía se ha vuelto una herramienta central del trabajo arqueológico.

Soledad Redes presentó una ponencia acerca de la vinculación entre caricaturas y fotografías en la revista Caras y Caretas (1890-1897), desglosando el origen de los retratos de las figuras políticas caricaturizadas y el doble rol de las imágenes cómicas de ridiculizar y popularizar el rostro de un líder político.

La última ponencia estuvo a cargo de Martín Cerchiari y Fernanda Aramuni, fotógrafos del Poder Legislativo, quienes expusieron una selección correctamente contextualizada de fotografías del Palacio Legislativo durante la dictadura (19771985), unas mil quinientas imágenes halladas en el lugar en el año 2016. En ella fue posible apreciar diversos detalles y elementos del funcionamiento del edificio durante el período, tanto siendo albergue del Consejo de Estado como sede para el recibimiento de visitas oficiales extranjeras, en un intento por legitimar el carácter pro-democrático del régimen.

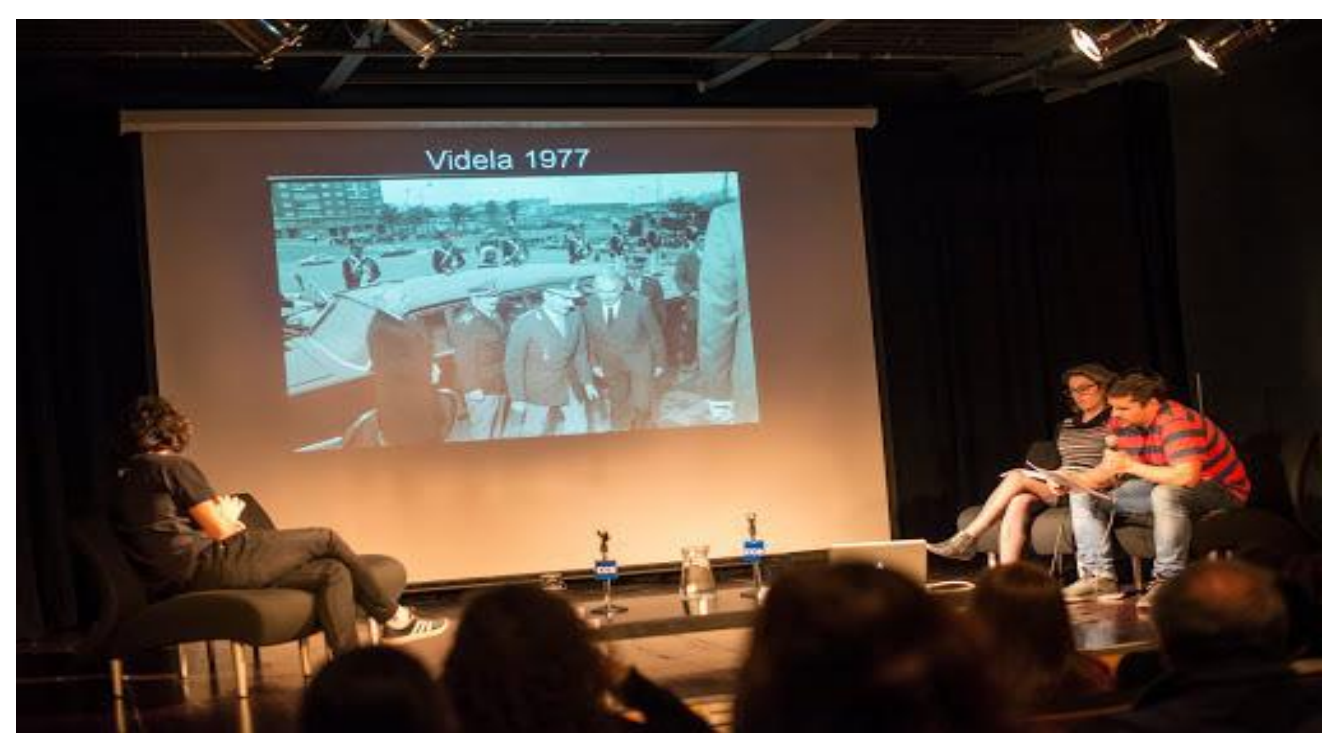

Martín Cerchiari y Fernanda Aramuni durante su presentación.

Foto: Centro de Fotografía de Montevideo. 
Por último, el evento sirvió de marco para la presentación de resultados del llamado a ediciones 2018 del CdF para las categorías de Libro de artículos de investigación sobre fotografía y Libro de investigación sobre fotografía. En el primer caso, los seleccionados fueron Alejandro León Cannock (Perú), Juan Peraza Guerrero (Venezuela) y Julieta Pestarino (Argentina). El libro de investigación de autor latinoamericano seleccionado fue el de Leticia Rigat (Argentina) La representación de los pueblos originarios en la fotografía latinoamericana contemporánea: de la imagen de identificación a la imagen de reconocimiento, mientras que la categoría libro de investigación de autor uruguayo se declaró desierta.

En su obra La cámara lúcida, Barthes expresaba en 1980 que es particular de la fotografía su capacidad de repetir "mecánicamente lo que nunca más podrá repetirse existencialmente”. Esta capacidad le otorga un potencial como documento histórico que está claro que no debería pasarse por alto, pero tampoco tomarse a la ligera. La incorporación de la fotografía exige conocer y aproximarse certeramente a su complejidad. Estimular que investigadores, docentes y estudiantes ahonden en el conocimiento de los fondos documentales que existen, las investigaciones que los abordan desde diversas disciplinas, las perspectivas metodológicas que aportan novedades a este trabajo, es sólo una parte del desafío que este evento se planteó como objetivo. Afianzar vínculos e intercambios en el seno de esta comunidad académica, que la fortalezcan y propicien nuevos abordajes, es otro de ellos.

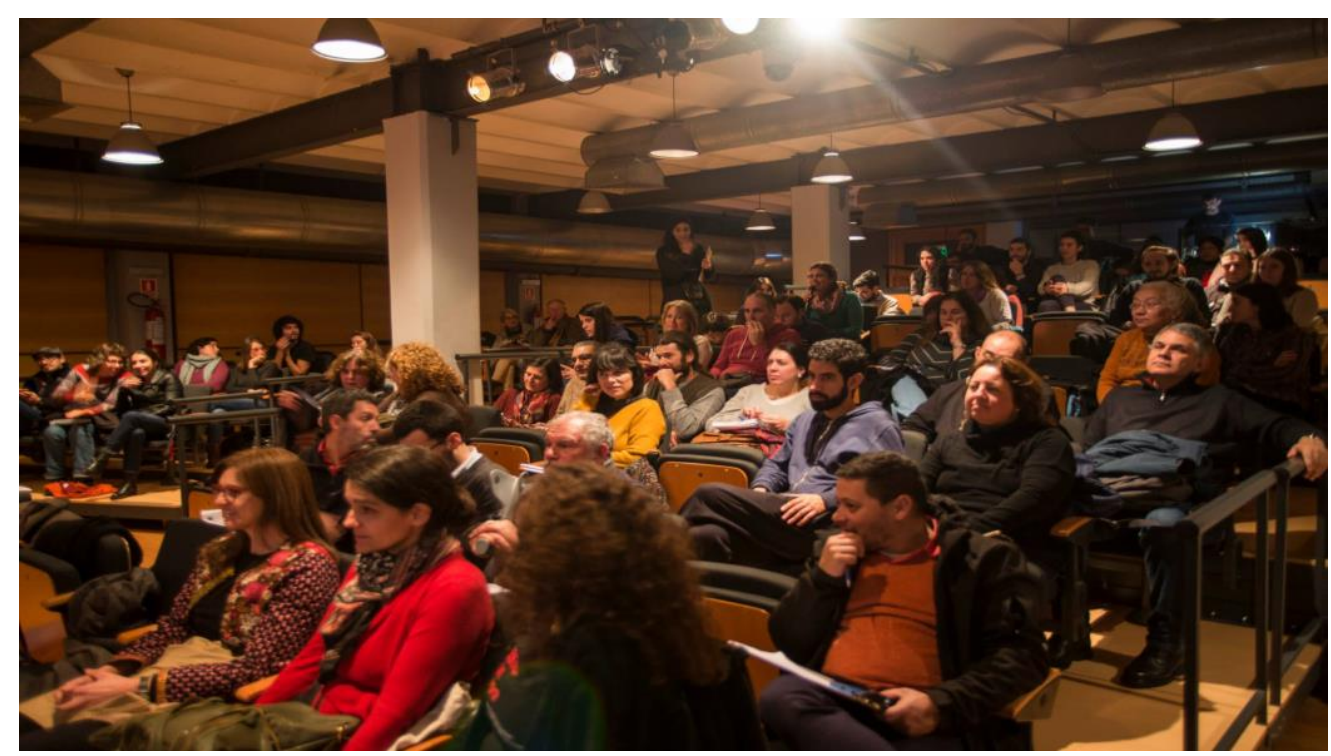

Público presente en una de las dos jornadas

Foto: Centro de Fotografía de Montevideo. 